\title{
Effect of mycorrhization and water stress on morphological parameters, concentration of phenolic compounds and antioxidant capacity of methanolic extract of Lupinus albus
}

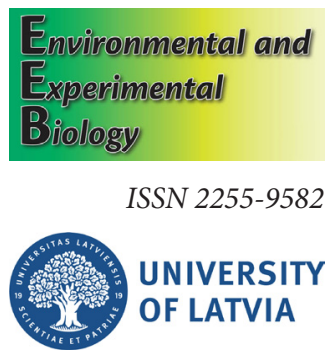

\author{
Siham Abaid', Salah Eddine Bachir Bouiadjra', Fawzia Toumi-Benali' \\ Fatima Dahlia ${ }^{2 *}$, Rachida Bouteldja ${ }^{3}$, Hebib Aggad ${ }^{3}$ \\ ${ }^{1}$ Laboratory of Eco-development of Spaces, Department of Environmental Sciences, Faculty of \\ Natural and Life Sciences, University of Djilali Liabes, Sidi Bel Abbes, Algeria \\ ${ }^{2}$ Laboratory of Plant Physiology Applied to Soilless Crops, Department of Natural and Life Sciences, \\ Faculty of Natural and Life Sciences, University of Ibn Khaldoun Tiaret, Algeria \\ ${ }^{3}$ Laboratory of Animal Hygiene and Pathology, Institute of Veterinary Sciences, University of Ibn \\ Khaldoun, Tiaret, Algeria
}

${ }^{\star}$ Corresponding author, E-mail: fdahlia84@gmail.com

\begin{abstract}
Secondary metabolites and mycorrhizal symbiosis play important roles in the adaptation of plants to environmental conditions, but mycorrhizal symbiosis favours also accumulation of secondary metabolites. Our objective was to study effect of interaction between mycorrhization and water deficiency on morphological parameters, phenolic compound concentration in Lupinus albus and to perform an evaluation of the antioxidant potential of methanolic extract of this plant. Plants of L. albus were subjected to three levels of water defficiency (80, 50 and 30\% of field capacity). Half of the plants in each treatment were inoculated with arbuscular mycorrhizal fungi. Total concentrations of polyphenols, flavonoids, and condensed tannins were measured, and antioxidant potential of methanolic extracts from leaves and roots of white lupin plants was evaluated. In general, mycorrhizal plants of L. albus had better growth indices in all watering regimes in comparison to non-mycorrhizal plants. The concentrations of phenolic compounds were maximal in the leaf extracts from L. albus plants inoculated with arbuscular mycorrhizal fungi grown under $30 \%$ of field capacity water regime, and in root extract of non-inoculated plants grown under 30\% of field capacity. Methanolic extracts of all plants showed good antioxidant activity, with higher values in mycorrhizal drought-stressed plants.
\end{abstract}

Key words: antioxidants, Lupinus albus, morphological parameters, mycorrhization, secondary metabolites, water stress. Abbreviations: AMF, arbuscular mycorrizal fungi; CE, catechin equivalent; DM, dry matter; DPPH, 1,1-diphenyl-2-picrylhydrazyl; FC, field capacity; GAE, gallic acid equivalent; QE, quercetin equivalent; ROS, reactive oxygen species.

\section{Introduction}

Lupinus albus L. is a legume plant; its seeds have been used as food and feed from ancient times due to their nutritional and therapeutic characteristics (Kinder, Knecht 2011). The green plant itself has been used extensively in some countries as forage and as an organic material for soil enrichment, or in crop rotation, because plant is capable of forming a symbiosis with rhizobacteria to fix atmospheric nitrogen (Yoneyama, Natsume 2010). L. albus is rich in bioactive molecules such as polyphenols, flavonoids and tannins, which have antioxidant properties (Petterson 2016; Karamać et al. 2018). Indeed, plants have evolved both enzymatic and non-enzymatic defense systems for scavenging and detoxifying reactive oxygen species (ROS), resulting in relatively high antioxidant defense capacity (Regnault et al. 2008).

Water shortage or drought stress is one of the most widespread environmental factors that negatively affects both crop growth and yield (Lisar et al. 2012). It has been extensively reported that drought stress results in inhibition of photosynthesis, increased oxidative stress and changes in metabolism of plants (Farooq et al. 2009; Sohrabi et al. 2012; Fahad et al., 2017; Michaletti et al. 2018; Kapoor et al. 2020; Parkash, Singh 2020). However, some antioxidant compounds such as ascorbic acid, rutin, quercetin, flavonoids and tannins, produced in plants play a significant role in scavenging ROS (Ashraf et al. 2018).

Arbuscular mycorrhizal fungi (AMF) are known to stimulate growth performance and to increase tolerance 
to unfavourable conditions such as drought (Bahadur et al. 2019). Mycorrhization can improve mineral nutrition of the host plant and forms an extended network of hyphae, considerably improving mineral nutrient absorption capacity of roots (Teotia et al. 2017). Moreover, symbiosis with AMF protects plants from unfavourable environmental conditions by inducing the enzymatic antioxidant system (Hashem et al. 2016) and stimulating accumulation of secondary metabolites (Walter, Strack 2011). Higher concentration of polyphenols, flavonoids and tannins has been observed in foliar and root parts of mycorrhizal plants under drought stress (Jugran et al. 2015). Mycorrhizal plants counteract water deficit-induced oxidative stress by enhancing capacity of antioxidant compound production and improved the enzymatic antioxidative activitiy (Sohrabi et al. 2012).

The objective of the present study was to assess the effect of mycorrhization on growth and phenolic compound levels of $L$. albus plants grown at different levels of water availability, and to evaluate antioxidant potential of methanolic extract of this plant.

\section{Materials and methods}

\section{Plant material and experimental conditions}

Seeds of white lupin, Lupinus albus L., were provided by the National Institute of Agronomic Research (INRA) of Sidi Bel Abbes (Algeria).

The experiment was carried out in a semi-controlled greenhouse at the Institut de Technologie Moyenne de l'Agriculture (ITMA) of Tiaret (Algeria). The plants were maintained in the greenhouse at conditions of $16 / 8 \mathrm{~h}$ light/ dark cycle, 252 lux light intensity, $28{ }^{\circ} \mathrm{C}$ and $60 \%$ relative humidity.

Native strains of mycorrhizae were used. These strains were trapped in leek (Allium porrum L.) roots. Leek plants were grown in non-sterile soil from the Tiaret area to trap spores of arbuscular mycorrhizal fungi. To ensure that trapping was successful and that leek roots were infected by the mycorrhizal fungi, arbuscular mycorrhizal structures were observed at the root level following the protocol of Kormanik and McGraw (1982) and Vierheilig et al. (1998).

L. albus seeds were disinfected as described by (Redon et al. 2009). The seeds were immersed in $30 \% \mathrm{H}_{2} \mathrm{O}_{2}$ for 5 min and then rinsed five times with distilled water. Seeds were then soaked in distilled water containing three drops of Tween 80 for 3 min and then rinsed several times with distilled water. Disinfected seeds were placed on moistened blotting paper at $20{ }^{\circ} \mathrm{C}$. The germination rate of a seed batch, calculated as the number of germinated seeds by the number of tested seeds, was $98 \%$.

Sterilized seeds were immediately placed in trays containing potting soil sterilized at $120{ }^{\circ} \mathrm{C}$ for $3 \mathrm{~h}$ in a ventilated oven. They were irrigated daily with demineralized water. After one week, $L$. albus seedlings were planted individually in plastic pots $(22 \mathrm{~cm}$ in height and $15 \mathrm{~cm}$ in diameter) filled with $6.5 \mathrm{~kg}$ of substrate [mixture of phosphorus-deficient calcareous soil and sand, 2:1 (v/v); Table 1].

Roots of leek plants infected with the mycorrhizal fungus were washed, cut into small pieces, mixed with sterilized substrate and used as an inoculum. The latter represented $10 \%$ of the total weight of substrate used in cultivation $(650 \mathrm{~g})$. The inoculum was placed at the base of the roots of seedlings transplanted according to the protocol of McGonigles et al. (1990). L. albus was used in two regimes (in the presence or absence of mycorrhizal inoculum) with three levels of water efficiency (80, 50 and $30 \%$ of field capacity, FC). Uninoculated plants cultivated under $80 \%$ of FC were considered as the control plants.

Ten days after sowing, different water regimes were applied to the plants at a rate of 30,50 and $80 \%$ of the field capacity until the end of the experiment. Soil field capacity was estimated by the following equation:

$$
\mathrm{FC}=[(\mathrm{W} 2-\mathrm{W} 1] / \mathrm{W} 2) \times 100,
$$

where FC is field capacity, W1 is dry weight of the substrate, W2 is substrate weight at saturation.

The experimental design was a total randomization with three replicates. Each replicate consisted of five plants in individual pots from the same treatment. The pots of AMF-inoculated plants were separated from the pots of AMF-uninoculated plants by a $10 \mathrm{~m}$ space to avoid fungal contamination. Five plants from each treatment in each replicate were used to give a total of 15 plants for the different measurements.

\section{Morphological parameters}

The length of roots was determined using a graduated tape measure. Root volume was measured by immersing the root system in a graduated cylinder filled with water, according to Archimedes' thrust principle: the volume of an immersed body is equal to the volume of the displaced liquid (difference in level).

Biomass of aerial parts and roots, both fresh and dry, were determined using a precision balance. Fresh weight

Table 1. Results of chemical analysis of the substrate (soil + sand) used in the experiment. Results are averages of 15 replicates. The methods of analysis as well as the expression of the results were performed according to Mathieu, Pieltain (2003)

\begin{tabular}{lc} 
Parameter (unit) & Value \\
$\mathrm{pH}$ & 8.12 \\
Organic matter (\%) & 2.73 \\
Total C (\%) & 22.73 \\
\hline Total N (\%) & 0.45 \\
\hline Potassium $\left(\mathrm{K}_{2} \mathrm{O}, \mathrm{mg} \mathrm{kg}^{-1}\right)$ & 18.70 \\
Available $\mathrm{P}\left(\mathrm{P}_{2} \mathrm{O}_{5}, \mathrm{mg} \mathrm{kg}^{-1}\right)$ & 11.52
\end{tabular}


was determined directly after plant removal from substrate. Dry weight was obtained after keeping plants in open air in the shade until a constant weight was obtained.

\section{Phytochemical analysis}

All leaves and roots of the white lupin plants from each treatment were recovered individually, homogenized, left to dry in the open air in shade until a constant weight was obtained and then used for extract preparation and determination of phenolic compounds. In order to preserve bioactive compounds, the leaves and the roots of $L$. albus were dried naturally and kept at ambient temperature.

The extraction of bioactive molecules was carried out according to the maceration method described by Dif et al. (2015) and by Liezhou et al. (2019). Each $0.2 \mathrm{~g}$ sample of dried leaves or roots of L. albus was macerated in a mortar containing $10 \mathrm{~mL} 80 \%$ methanol. After vortex homogenization, the mixture was filtered on filter paper No. 1 and preserved at $-20{ }^{\circ} \mathrm{C}$ until use as recommended by $\mathrm{Dif}$ et al. (2015).

Polyphenols were determined with the Folin-Ciocalteu reagent, which in alkaline medium are reduced to tungstenmolybdenum oxide, giving a blue color in the presence of polyphenols (Bouyahya et al. 2017). A sample (125 $\mu \mathrm{L})$ of extract was added to $125 \mu \mathrm{L}$ Ciocalteu-Folin reagent (1:10, $\mathrm{v} / \mathrm{v})$. The solutions were mixed and incubated for $3 \mathrm{~min}$ at room temperature. After incubation, $1250 \mu \mathrm{L} 20 \% \mathrm{Na}_{2} \mathrm{CO}_{3}$ solution was added. The mixture was then adjusted with 1 $\mathrm{mL}$ distilled water and incubated for $90 \mathrm{~min}$ in the dark at room temperature. The absorbance was measured at 760 nm (Rover, Brown 2013).

The quantification of flavonoids was carried out using the colorimetric method with $\mathrm{AlCl}_{3}$ and $\mathrm{NaOH}$. $\mathrm{AlCl}_{3}$ forms a yellow complex with flavonoids and $\mathrm{NaOH}$ forms a pink complex that absorbs in visible light at 510 $\mathrm{nm}$ according to the method described by Hebi, Eddouks (2015). $250 \mu \mathrm{L}$ extract and $1 \mathrm{~mL}$ distilled water were added to $75 \mu \mathrm{L} 5 \% \mathrm{NaNO}_{2}$ solution. After 6 min incubation at room temperature, $150 \mu \mathrm{L}$ of a freshly prepared aluminum chloride solution $(\mathrm{AlCl} 3,10 \%)$ was added to the previous mixture. After $5 \mathrm{~min}$ rest, still at room temperature, $500 \mu \mathrm{L}$ $1 \mathrm{~N} \mathrm{NaOH}$ was added. The resulting homogeneous mixture was adjusted to $2500 \mu \mathrm{L}$ with distilled water (Hebi, Eddouks 2015).

Condensed tannins were determined by the vanillin method in acidic medium. This method is based on the ability of vanillin to react with the condensed tannin units in the presence of acid to produce a color complex measured at $550 \mathrm{~nm}$ (Palacios et al. 2021). A volume of $50 \mu \mathrm{L}$ of each extract was added to $1500 \mu \mathrm{L} 4 \%$ vanillin/ methanol solution and then mixed vigorously. Next, a volume of $750 \mu \mathrm{L}$ of concentrated $\mathrm{HCl}$ was added. The resulting mixture was allowed to react at room temperature for $20 \mathrm{~min}$. Absorbance was measured at $550 \mathrm{~nm}$ against a blank (Ali-Rachedi et al. 2018).

\section{Determination of antioxidant activity}

In the antioxidant test, the antioxidants reduce the purplecolored 1,1-diphenyl-2-picrylhydrazyl radical (DPPH) to a yellow compound (Brand-Williams et al. 1995; AliRachedi et al. 2018). An extract sample (1 mL) from leaves or roots of L. albus was added to $1 \mathrm{~mL}$ DPPH solution. DPPH solution was prepared by solubilizing $0.004 \mathrm{mg}$ of this product in $100 \mathrm{~mL}$ methanol. The mixture was left in the dark for $30 \mathrm{~min}$, and then the solutions were read with an UV spectrophotometer at $517 \mathrm{~nm}$ against a negative control containing only DPPH solution alone, which was prepared under the same conditions, and its absorbance was recorded. The positive control was represented by standard antioxidant ascorbic acid (Sanchez-Morzeno 2002; Pyrzynska, Pękal 2013). The results of anti-free radical activity were expressed as a percentage inhibition (I $\%)$ estimated according to the following equation:

$\mathrm{DPPH}$ scavenging effect $(\%)=[(\mathrm{A} 0-\mathrm{A} 1) / \mathrm{A} 0] \times 100$, where $\mathrm{A} 0$ is the absorbance of the blank and $\mathrm{A} 1$ is the absorbance of the sample.

\section{Data analysis}

Analysis of variance was performed using SPSS V.25.0 statistical software. The results were presented as the mean with its standard deviation. The determination of significance was performed using the ANOVA test. Differences were considered significant at $P \leq 0.05$.

\section{Results}

\section{Morphological parameters}

L. albus plants inoculated with AMF, regardless of the level of water stress, had higher values for morphological parameters (average of stem height, fresh and dry weight of aerial parts and roots, root length, root volumes) than nonmycorrhizal plants (Table 2). The highest value for stem height of plants was recorded in plants cultivated at $80 \%$ FC (both mycorrhizal and non-mycorrhizal) and it decreased with severity of water shortage.

The weight of fresh aerial biomass was higher in inoculated plants gown at $80 \%$ FC. It was lower in noninoculated plants as well as when drought was higher (Table 2). Simultaneously, the weight of dry aerial biomass was higher in mycorrhizal plants grown at 50\% FC and this parameter did not significantly differ in inoculated plants grown at 80 and $30 \% \mathrm{FC}$ and in uninoculated plants grown at $50 \% \mathrm{FC}$. The parameter was lower in uninoculated plants at $30 \% \mathrm{FC}$.

The longest roots were from $L$. albus plants cultivated at $30 \%$ FC (Table 2). The inoculated plants grown at $30 \%$ FC had roots $28.6 \%$ longer than these for non-inoculated plants at the same water regime. The shortest roots were found in plants grown at $80 \%$ FC. These plants also showed the highest root volume and fresh root biomass. The mean values of the latter two parameters were lower in the case 
Table 2. Means of morphological parameters of Lupinus albus. Values represent the mean of three replicates \pm standard deviation (each replication is the mean of values of five plants). Identical letters represent homogeneous groups according to a Tukey test when the trait was significantly different at the level of $P<0.05$

\begin{tabular}{llcccc} 
Parameter & FC $(\%)$ & \multicolumn{2}{c}{ Aerial parts } & \multicolumn{2}{c}{ Roots } \\
\cline { 3 - 6 } & & Non-mycorrhizal & Mycorrhizal & Non-mycorrhizal & Mycorrhizal \\
Length $(\mathrm{cm})$ & 80 & $17.05 \pm 0.67 \mathrm{~B}$ & $24.77 \pm 3.40 \mathrm{~b}$ & $13.00 \pm 1.73 \mathrm{~A}$ & $8.25 \pm 2.35 \mathrm{a}$ \\
& 50 & $9.27 \pm 1.59 \mathrm{~A}$ & $14.50 \pm 2.29 \mathrm{a}$ & $12.17 \pm 2.22 \mathrm{~A}$ & $14.39 \pm 2.08 \mathrm{~b}$ \\
& 30 & $8.46 \pm 1.78 \mathrm{~A}$ & $11.26 \pm 1.03 \mathrm{a}$ & $14.17 \pm 1.03 \mathrm{~A}$ & $18.26 \pm 2.15 \mathrm{~b}$ \\
\hline Volume $(\mathrm{mL})$ & 80 & - & - & $22.67 \pm 2.31 \mathrm{~B}$ & $22.67 \pm 3.06 \mathrm{~b}$ \\
& 50 & - & - & $14.67 \pm 2.31 \mathrm{~A}$ & $19.33 \pm 1.16 \mathrm{ab}$ \\
\hline Fresh biomass $(\mathrm{g})$ & 80 & - & - & $12.09 \pm 2.25 \mathrm{~A}$ & $16.66 \pm 2.25 \mathrm{a}$ \\
& 50 & $4.393 \pm 0.014 \mathrm{~B}$ & $6.507 \pm 1.756 \mathrm{a}$ & $1.072 \pm 0.094 \mathrm{C}$ & $1.603 \pm 0.179 \mathrm{~b}$ \\
\hline & 30 & $4.594 \pm 0.04 \mathrm{~B}$ & $5.443 \pm 1.264 \mathrm{a}$ & $0.512 \pm 0.056 \mathrm{~B}$ & $0.666 \pm 0.110 \mathrm{a}$ \\
\hline Dry biomass $(\mathrm{g})$ & 80 & $1.219 \pm 0.069 \mathrm{~A}$ & $3.648 \pm 0.02 \mathrm{a}$ & $0.252 \pm 0.032 \mathrm{~A}$ & $0.402 \pm 0.022 \mathrm{a}$ \\
\hline & 50 & $0.585 \pm 0.025 \mathrm{~B}$ & $0.857 \pm 0.022 \mathrm{a}$ & $0.103 \pm 0.004 \mathrm{~A}$ & $0.084 \pm 0.040 \mathrm{a}$ \\
& 30 & $0.807 \pm 0.028 \mathrm{C}$ & $0.932 \pm 0.022 \mathrm{a}$ & $0.119 \pm 0.025 \mathrm{~A}$ & $0.114 \pm 0.020 \mathrm{a}$ \\
\hline
\end{tabular}

of severe water shortage in the absence of mycorrhizal inoculum, as the lowest values were recorded in nonmycorrhizal plants grown at 30\% FC.

The dry root biomass of lupin plants ranged from 0.084 to $0.119 \mathrm{~g}$ (Table 2 ). This parameter appeared to be relatively insensitive to the presence or absence of mycorrhizal inoculum and the severity of the water shortage.

\section{Phytochemical analysis}

The total polyphenol assay showed that the methanolic extract of leaves of L. albus contained highest polyphenol concentration compared to root extract (Table 3). Leaves of AMF-inoculated plants grown under 30\% FC had the highest total polyphenol concentration (Table 3), which was $93.8 \%$ higher than in control plants extract (uninoculated plants grown under $80 \%$ FC). Leaf extracts from mucorrhizal L. albus plants cultivated under $80 \%$ FC had the lowest total polyphenol concentration, which was by $50.3 \%$ lower than in extract from control plants. An increase by $26.5 \%$ in polyphenol concentration was evident in the methanolic leaf extracts of non-mycorrhizal L. albus plants grrown at FC of 50\%, compared to the leaf extracts of control plants (Table 3).

The highest level of polyphenols was recorded in root extracts from uninoculated plants cultivated at $30 \%$ FC (59.8\% higher than control) and root extracts from inoculated plants grown at 50\% FC (30.6\% higher than the control). However, the lowest level of polyphenols occurred in root extracts of mycorrhizal plants grown at FC 30 and $80 \%$, with respective values being $48.0 \%$ and $44.2 \%$ lower than in control plants (Table 3 ).

Extracts from leaves of inoculated plants grown at $30 \%$

Table 3. Concentration of total polyphenols, flavonoids, condensed tannins in methanolic extracts from leaves and roots of Lupinus albus and their percentages of inhibition of free radicals (antioxidant activity). Values represent the mean of three replicates \pm standard deviation (each replication is the mean of values of five plants). Identical letters represent homogeneous groups according to a Tukey test when the trait was significantly different at the level of $P<0.05$

\begin{tabular}{|lccccc} 
Parameter (unit) & FC (\%) & \multicolumn{2}{c}{ Leaves } & \multicolumn{2}{c}{ Roots } \\
\cline { 2 - 6 } & & Non-mycorrhizal & Mycorrhizal & Non-mycorrhizal & Mycorrhizal \\
Polyphenols (mg GAE g-1 DM) & 80 & $4.81 \pm 2.92 \mathrm{~A}$ & $2.39 \pm 0.43 \mathrm{a}$ & $2.45 \pm 0.68 \mathrm{~A}$ & $1.37 \pm 0.32 \mathrm{a}$ \\
& 50 & $6.08 \pm 0.88 \mathrm{~A}$ & $5.36 \pm 1.35 \mathrm{~b}$ & $2.62 \pm 0.25 \mathrm{~A}$ & $3.20 \pm 1.28 \mathrm{~b}$ \\
& 30 & $4.37 \pm 2.66 \mathrm{~A}$ & $9.31 \pm 0.53 \mathrm{c}$ & $3.92 \pm 0.79 \mathrm{~B}$ & $1.28 \pm 0.29 \mathrm{a}$ \\
\hline Flavonoids (mg QE g-1 DM) & 80 & $1.91 \pm 1.51 \mathrm{~A}$ & $1.27 \pm 0.29 \mathrm{a}$ & $1.06 \pm 0.12 \mathrm{~A}$ & $0.24 \pm 0.26 \mathrm{a}$ \\
& 50 & $2.63 \pm 1.01 \mathrm{~A}$ & $1.57 \pm 0.17 \mathrm{a}$ & $1.20 \pm 0.11 \mathrm{~A}$ & $2.54 \pm 1.07 \mathrm{~b}$ \\
& 30 & $1.21 \pm 0.33 \mathrm{~A}$ & $6.75 \pm 0.79 \mathrm{~b}$ & $1.82 \pm 0.29 \mathrm{~B}$ & $1.45 \pm 0.10 \mathrm{ab}$ \\
\hline Tannins (mg CE g $\left.{ }^{-1} \mathrm{DM}\right)$ & 80 & $0.55 \pm 0.36 \mathrm{~A}$ & $0.32 \pm 0.04 \mathrm{a}$ & $0.66 \pm 0.04 \mathrm{~B}$ & $0.57 \pm 0.07 \mathrm{~b}$ \\
& 50 & $0.29 \pm 0.03 \mathrm{~A}$ & $0.28 \pm 0.05 \mathrm{a}$ & $0.38 \pm 0.03 \mathrm{~A}$ & $0.38 \pm 0.01 \mathrm{a}$ \\
\hline Antioxidant activity (\%) & 30 & $0.30 \pm 0.04 \mathrm{~A}$ & $0.33 \pm 0.09 \mathrm{a}$ & $0.42 \pm 0.01 \mathrm{~A}$ & $0.36 \pm 0.01 \mathrm{a}$ \\
& 80 & $71.26 \pm 4.48 \mathrm{AB}$ & $82.54 \pm 2.13 \mathrm{a}$ & $95.63 \pm 0.68 \mathrm{C}$ & $86.30 \pm 1.49 \mathrm{a}$ \\
\hline & 50 & $85.84 \pm 2.243 \mathrm{~B}$ & $73.97 \pm 14.53 \mathrm{a}$ & $90.82 \pm 1.50 \mathrm{~B}$ & $92.58 \pm 1.23 \mathrm{a}$ \\
\hline
\end{tabular}


FC had $253.9 \%$ higher flavonoid concentration than in extract from control plants (Table 3). Leaf extracts from non-mycorrhizal plants cultivated at 50\% FC had $37.9 \%$ higher flavonoid concentration than from control plants. However, inoculated plants grown at 50 and $80 \%$ FC, and inoculated plants grown at $30 \%$ of FC had leaf extracts with $17.9,33.4$ and $36.5 \%$ lower flavonoid concentration than control plants, respectively.

Extracts from roots of inoculated plants grown at 50\% FC had the highest concentration of flavonoids (40.5\% higher flavonoid concentration, compared to control plants; Table 3). The lowest flavonoid concentration was found in root extracts of mycorrhyzal plants cultivated at $80 \%$ FC $(77.6 \%$ lower flavonoid concentration than for control plants). Inoculated drought-stressed plants $(30 \%$ FC) and uninoculated drought-stressed plants (30 and 50\% FC) had also higher flavonoid concentration than control plants (37.0, 72.4 and 22.8\% more, respectively).

Methanolic extract of leaves and roots of control plants $(80 \%$ FC) had the highest values of condensed tannins (Table 3). Methanolic extracts of roots had higher concentration of tannins than leaf extracts. Leaf extract of mycorrhizal plants had more tannins than that of nonmycorrhizal plants. However, at the root level, extracts of non-inoculated plants had higher tannin concentration.

Leaf extracts of inoculated and uninoculated plants grown at 50\% FC had the lowest concentration of tannins (Table 3). They contained 49.0 and $47.1 \%$ lower tannin concentration than control plants, respectively. Root extracts of inoculated plants growing at 30\% FC had the lowest tannin concentration $(45.3 \%$ lower than that of control plants).

\section{Antioxydant activity}

The The antioxidant activity of leaf and root extracts was estimated by the percentage inhibition of free radicals. All tested methanolic extracts of L. albus showed relatively high antioxidant activity (Table 3). However, this parameter was relatively insensitive to mycorrhizal status of plants and conditions of water availability. Antioxidant activity significantly decreased with diminishing of water supply only in root extracts of non-mycorrhizal plants. When drought-stressed (30\% FC) plants were compared, mycorrhization resulted in significantly higher antioxidant activity in both leaf and roots extracts in comparison to that in non-mycorrhizal plants.

\section{Discussion}

Growth and morphological characteristics of Lupinus albus plants were significantly affected by water shortage and by plant mycorrhizal status. Drought stress at the levels of 50 and $30 \%$ of FC reduced plant size (by $15.0 \%$ and $53.1 \%$ ), weight of aerial parts (by 17.0 and $72.3 \%$ ) and root biomass (by 37.9 and $76.4 \%$ ), but increased roots length (by 7.7 and $38.5 \%$ ) of both inoculated and uninoculated plants, respectively (Table 2 ). It has been already shown that water deficit clearly affects morphological characteristics of plants in the absence of mycorrhizal association by reducing growth of vegetative parts (Mahmoudi et al. 2017).

Water shortage significantly suppresses cell growth due to the low turgor pressure (Shao et al.2008) resulting in low cell metabolism resulting in inhibition of both cell division and elongation (Singh et al.2018). Reduction in plant height is usually associated with a decline in cell enlargement and induction of leaf senescence (Bhatt, Srinivasa Rao 2005). Under severe drought stress, cell elongation of plants is inhibited by interruption of water flow from xylem to the surrounding elongating cells (Esmaeilpour et al. 2015). Drought stress inhibits dry matter production largely through its inhibitory effects on leaf expansion and leaf development (Anjum et al. 2011). In contrast, larger length of the root system provides plant access to a greater volume of soil for water acquisition (Sánchez-Blanco et al. 2014). This elongation of the main root leads to a better exploration of deep horizons and consequently a better absorption of water when its presence is limited in the superficial layers of the soil, which explains why roots of drought-stressed $L$. albus plants were longer than these of the plants grown at optimum water supply.

Mycorrhizal symbiosis improved morphological traits of drought-stressed L. albus plants. In the presence of mycorrhizal inoculation, roots were longer, with larger volume and with more fresh mass as compared to those of non-inoculated plants grown under water shortage conditions (Table 2). Mycorrhizal inoculation also promoted development of aerial parts, evident as an increase in plant height, fresh and dry mass compared to non-inoculated plants subjected to drought stress conditions. Similar to the results of the present study, inoculation of Acacia seyal by Glomus aggregatum stimulated the development of fresh biomass of the aerial and root parts in the situation of stress (Manga et al. 2018). Also, arbuscular mycorrhization had a positive impact on improvement of tolerance to water stress in Phaseolus vulgaris, resulting in an increase in dry root and aerial biomass in stressed inoculated plants compared to non-inoculated stressed plants (Ganjeali et al. 2017). Other studies also reported that plants inoculated with AMF produced more dry weight than control plants (Thakur, Shinde 2020).

It has been already demonstrated that mycorrhization improves plant performance in conditions of drought stress. Several studies showed that inoculation with AMF increased plant height, biomass and dry weight in Solanum lycopersicum (Ruiz-Lozano et al. 2015; Chitarra et al. 2016); increased plant height, biomass, shoot and root dry matter, root length, shoot length in Lycopersicon esculentum (Subramanian et al. 2006; Padmavathi et al. 2016); increased biomass, water content and reduced antioxidant compounds in Lavandula spica (Marulanda 
et al. 2007); increased fresh and dry weight in Allium cepa (Nelsen, Safir 1982); and increased shoot and root weight and flavonoid concentration in Pistacia vera (Abbaspour et al. 2012). Water uptake per unit root length in mycorrhizal plants was twice as high as in control plants (Boutasknit et al. 2020; Gurdeep Singh et al. 2021). In addition, root volume increases in inoculated plants subjected to different water stress conditions, because mycorrhizal association is beneficial for production of new roots, their proliferation (increased root volume), their elongation (increase in length) and their maintenance under the effect of water deficit (Zou et al. 2017; Wu, Zou, 2017; He et al. 2019).

Besides increase in plant growth, mycorrhizal inoculation increased concentration of phytochemical constituents (total phenolics, tannins, and flavonoids; Table 3). Total polyphenol and flavonoid concentration increased, but tannin concentration decreased in leaves of non-inoculated plants grown at 50\% FC and in roots of non-inoculated plants cultivated at $30 \% \mathrm{FC}$, in comparison to control plants grown at $80 \%$ FC. In leaves of mycorrhizal plants, concentration of total polyphenols and flavonoids increased with increasing severity of water shortage. However, the highest levels of polyphenols and flavonoids in roots of inoculated plants were obtained in the $50 \% \mathrm{CF}$ plants. It has been reported that under the effect of water deficit, the phenolic concentration of the aerial and root parts significantly increased in stressed and mycorrhized plants, compared to non-mycorrhized plants (Benjelloun et al. 2014; Koné et al. (2019). In this context, flavonoids play a role in plant-arbuscular mycorrhizal fungi interactions and their concentration was maximal in response to water deficit (De Matos et al. 2014). Flavonoids have the potential to help plants tolerate, resist and escape water stress (Shah, Smith 2020). It was found that there is a positive correlation between root flavonoids, water supply and AMF colonization (Pei et al. 2020).

Concerning mycorrhizal inoculation of $L$. albus in the present study, concentration of phenolic compounds increased significantly in leaf and root extracts, as compared to non-inoculated plants under water shortage conditions. The most likely mechanism involved in increasing concentration of certain phytochemicals is the improved nutrition that AMF can provide to plants (Crişan et al. (2018). High production of phenolic compounds may be related to an increased activity of enzymes such as chalcone synthase and chalcone isomerase, which are involved in the synthesis of flavonoids, and phenylalanine ammonia lyase, responsible for catalyzing the deamination of phenylalanine, which is an important regulating stage in the formation of phenolic compounds, and which may have its activity increased by environmental factors and by biotic factors, such as colonization by fungi (PedoneBonfim et al. 2015).

Water deficit also induces endogenous oxidative stress with the formation of ROS and free radicals, which are very harmful to cellular constituents (Bouchemal et al. 2018).
As a response to increased ROS, plants have developed protective mechanisms, involving both induction of the enzymatic antioxidative system and accumulation of nonenzymatic antioxidants. This mechanism may be associated with plant resistance to water deficit (Cruz De Carvalho 2008; Gill, Tuteja 2010).

In the present study, capacity of extracts for free radical removal in leaves of L. albus mycorrhizal plants grown at $30 \%$ of FC and in leaves of non-mycorrhized plants grown at $50 \%$ of FC were higher than in control plants (Table 3). Root extracts of mycorrhized L. albus subjected to 30 and $50 \%$ of FC had higher antioxidant activity as compared to the non-inoculated plants subjected to the same water shortage conditions. Similarly, a number of studies have confirming that antioxidant levels increased in plants under water stress and in the presence of mycorrhizal colonization (Abreu, Mazzafera 2005; Mohamed, Latif 2017; Ghassemi et al. 2019). In particular, concentration of ROS in leaves and roots of mycorrhizal stressed plants was significantly lower as compared to non-mycorrhizal plants (Babita et al. 2018). Moreover, mycorrhizal colonization decrease the level of ROS in the aerial and root parts of the host plant through the enhancement of antioxidant activities in mycorrhizal plants (Wu et al. 2014; Chen et al. 2020). Increase in antioxidants resulted in a lower accumulation of ROS than in non-mycorrhizal plants, indicating lower oxidative damage in symbiotic plants.

\section{Conclusions}

The obtained results indicate clearly that arbuscular mycorrhizal fungi had the potential to improve plant growth and development, and increase antioxidant activity and phenolic compound concentration in leaf and root methanolic extracts of $L$. albus, thereby reducing the negative impact of water stress. Our study results can provide perspective means to increase supply of bioactive molecules.

\section{Acknowledgements}

We would like to express gratitude to all the staff of the Laboratory of Animal Hygiene and Pathology, Institute of Veterinary Sciences, University of Ibn Khaldoun, Tiaret, Algeria, for agreeing to produce this work and to be part of its research axis. This research did not receive any specific grant from funding agencies in the public, commercial, or not-for-profit sectors. All authors declare that they have no interest conflict. Siham Abaid, Salah Eddine Bachir-Bouiadjra and Fawzia Toumi-Benali conceived and designed the research. Siham Abaid, Fatima Dahlia, Rachida Bouteldja, Hebib Aggad performed the experiments. Siham Abaid and Fatima Dahlia analysed the data wrote the manuscript.

\section{References}

Abbaspour H., Saeidi-Sar S., Afshari H., Abdel-Wahhab M., Abdel-Wahhab M.A. 2012. Tolerance of mycorrhiza infected pistachio (Pistacia vera L.) seedling to drought stress under 
glasshouse conditions. J. Plant Physiol. 169: 704-709.

Abreu I.N., Mazzafera P. 2005. Effect of water and temperature stress on the concentration of active constituents of Hypericum brasiliense Choisy. Plant Physiol. Biochem. 43: 241-248.

Ali-Rachedi F., Meraghni S., Touaibia N., Mohamed S. 2018. Quantitative analysis of the phenolic compounds of Algerian endemic (Scabiosa atropurpurea sub. maritima L.). Bull. Royal Soc. Sci. Liège 87: 13-21.

Anjum S.A., Xie X.Y, Wang L.C., Saleem M.F., Man C., Lei W., 2011. Morphological, physiological and biochemical responses of plants to drought stress. African J. Agric. Res. 6: 2026-2032.

Ashraf M. A., Iqbal M., Rasheed R., Hussain I., Riaz M., Arif M.S. 2018. Environmental stress and secondary metabolites in plants: An overview. In: Ahmad et al. (eds.) Plant Metabolites and Regulation Under Environmental Stress. Academic Press, pp. 153-167.

Babita R., Shashi M., Sharma K.D., Pooja, Ashwani K. 2018. Influence of arbuscular mycorrhiza on antioxidative system of wheat (Triticum aestivum) under drought stress. Indian J. Agric. Sci. 88: 289-295.

Bahadur A., Batool A., Nasir F., Jiang S., Mingsen Q., Zhang Q., Pan J., Liu Y., Feng H. 2019. Mechanistic insights into arbuscular mycorrhizal fungi-mediated drought stress tolerance in plants. Int. J. Mol. Sci. 20: 4199.

Benjelloun S., El Harachi E.H., Amrani Joutei K., El Ghachtouli N., Fikri Benbrahim K., El Yamani J. 2014. Study of the importance of mycorrhization on the synthesis of phenolic compounds in maize (Zea mays L.) under water stress. Appl. Biol. Chem. 59: 813-820.

Bhatt R.M., Srinivasa Rao N.K. 2005. Influence of pod load response of okra to water stress. Indian J. Plant Physiol. 10: 54-59.

Bouchemal K., Bouldjadj R., Belbekri M.N., Ykhlef N., Djekoun A. 2018. Photosynthetic pigments, antioxydant enzymes and leaf osmotic potential of ten durum wheat (Triticum durum) genotypes: impact of water stress. Phytoprotection 98: 13-24

Boutasknit A., Baslam M., Ait-El-Mokhtar M., Anli M., BenLaouane R., Douira A., El Modafar Ch., Mitsui T., Wahbi S., Meddich A. 2020. Arbuscular mycorrhizal fungi mediate drought tolerance and recovery in two contrasting carob (Ceratonia siliqua L.) ecotypes by regulating stomatal, water relations, and (in)organic adjustments. Plants 9: 80.

Bouyahya A., Abrini J., Bakri Y., Dakka N. 2017. Screening phytochimique et évaluation de l'activité antioxydante et antibactérienne des extraits d'Origanum compactum. Phytotherapie 15: 379-383.

Brand-Williams W., Cuvellier M.E., Berset C. 1995. Use of a free radical method to evaluate antioxidant activity. LWT Food Sci. Technol. 28: 25-30.

Chen W., Meng P., Feng H., Wang C. 2020. Effects of arbuscular mycorrhizal fungi on growth and physiological performance of Catalpa bungei C.A.Mey. under drought stress. Forests 11: 1117.

Chitarra W., Pagliarani C., Maserti B., Lumini E., Siciliano I., Cascone P., Schubert A., Gambino G., Balestrini R., Guerrieri E. 2016. Insights on the impact of arbuscular mycorrhizal symbiosis on tomato tolerance to water stress. Plant Physiol. 171: 1009-1023.

Crişan I., Vidican R., Stoian V. 2018. Induced modifications on secondary metabolism of aromatic and medicinal plants - An endomycorrhizal approach. Hop Medic. Plants 1- 2: 15-29.

Cruz De Carvalho M.H. 2008. Drought stress and reactive oxygen species production, scavenging and signaling. Plant Sign. Behav. 3: 156-165.

De Matos Nunes J., Bertodo L.O.O., Da Rosa L.M.G., Von Poser G.L., Rech S.B. 2014. Stress induction of valuable secondary metabolites in Hypericum polyanthemum acclimatized plants. South African J. Bot. 94: 182-189.

Dif M.M., Benchiha H., Mehdadi Z., Benali-Toumi F., Benyahia M., Bouterfas K. 2015. Quantification study of polyphenols in different organs of Papaver rhoeas L. Phytotherapie 13: 314319.

Esmaeilpour A., Van Labeke M.C., Samson R., Ghaffaripour S., Van Damme P. 2015. Comparison of biomass productionbased drought tolerance indices of pistachio (Pistacia vera L.) seedlings in drought stress conditions. Int. J. Agron. Agric. Res. $7: 36-44$.

Fahad S., Bajwa A.A., Nazir U., Anjum S.A., Farooq A., Zohaib A., Sadia S., Nasim W., Adkins S., Saud S., Ihsan M.Z., Alharby H., Wu C., Wang D., Huang J., 2017. Crop production under drought and heat stress: plant responses and management options. Front. Plant Sci. 8: 1147.

Farooq M., Wahid A., Kobayashi N., Fujita D., Basra S.M.A. 2009. Plant drought stress: effects, mechanisms and management. Agron. Sust. Dev. 29: 185-212.

Ganjeali A., Ashiani E., Zare M., Tabasi E. 2017. Influences of the arbuscular mycorrhizal fungus Glomus mosseae on morphophysiological traits and biochemical compounds of common bean (Phaseolus vulgaris) under drought stress. South African J. Plant Soil 35: 121-127.

Ghassemi S., Ghassemi-Golezani K., Salmasi S.Z. 2019. Changes in antioxidant enzymes activities and physiological traits of ajowan in response to water stress and hormonal application. Sci. Hortic. 246: 957-964.

Gill S.S., Tuteja N. 2010. Reactive oxygen species and antioxidant machinery in abiotic stress tolerance in crop plants. Plant Physiol. Biochem. 48: 909-930.

Hashem A., Abd_Allah E.F., Alqarawi A.A., Al-Huqail A.A., Wirth S., Egamberdieva D. 2016. The interaction between arbuscular mycorrhizal fungi and endophytic bacteria enhances plant growth of Acacia gerrardii under salt stress. Front. Microbiol. 7: 1089 .

He J.-D., Dong T., Wu H.-H., Zhou Y.-N., Wu Q.-S., Kuča K. 2019. Mycorrhizas induce diverse responses of root TIP aquaporin gene expression to drought stress in trifoliate orange. Sci. Hortic. 243: 64-69.

Hebi M., Eddouks M. 2015. Évaluation de l'activité antioxydante de Stevia rebaudiana. Phytothérapie 14: 17-22.

Jugran A., Bahukhandi A., Dhyani P., Bhatt I.D., Rawal R., Nandi S., Palni L.M. 2015. The effect of inoculation with mycorrhiza: AM on growth, phenolics, tannins, phenolic composition and antioxidant activity in Valeriana jatamansi Jones. J. Soil Sci. Plant Nutr. 15: 1036-1049.

Kapoor D., Bhardwaj S., Landi M., Sharma A., Ramakrishnan M., Sharma A. 2020. The impact of drought in plant metabolism: how to exploit tolerance mechanisms to increase crop production. Appl. Sci. 10: 5692.

Karamać M., Orak H.H., Amarowicz R., Orak A., Piekoszewski W. 2018. Phenolic concentrations and antioxidant capacities of wild and cultivated white lupin (Lupinus albus L.) seeds. Food Chem. 258: 1-7.

Kinder D.H., Knecht K.T. 2011. Lupine (Lupinus caudatus L., Lupinus albus L.) seeds: history of use, use as an antihyperglycemic medicinal, and useas a food. In: Preedy 
V.R., Patel V.B. (eds.) Nuts and Seeds in Health and Disease Prevention. Academic Press, pp. 711-716.

Koné D., Kouadio O., Kouadio S., Tuo S., N'cho Achi L., N’Guessan Affoué S.R., Kouakou T.H. 2019. Impact of water deficit on morpho-physiological parameters of young roselle plants (Hibiscus sabdariffa var sabdariffa). Int. J. Adv. Agric. Res. 7: 128-137.

Kormanik P.P., McGraw A.C. 1982. Quantification of vesiculararbuscular mycorrhizae in plant roots. In: Schenck N.C. (ed.) Methods and Principles of Mycorrhizal Research. The American Phytopathological Society, St. Paul, pp. 37-45.

Liezhou Z., Gangcheng W., Zhong-Xiang F., Mark L.M., Jonathan M., Hodgson M.W., Edwin J., Stuart K.J. 2019. Characterization of polyphenols in Australian sweet lupin (Lupinus angustifolius) seed coat by HPLC-DAD-ESI-MS/MS. Food Res. Int. 116: 1153-1162.

Lisar S.S.Y., Motafakkerazad R.M.M., Rahm M.I.M. 2012. Water stress in plants: causes, effects and responses.In: Rahman I.M.M., Hasegawa H. (eds.) Water Stress. Intech Open, Rijeka, pp. 1-14.

Mahmoudi N., Mahdhi M., Abdedaiem R., Bessadok K., Mars M. 2017. Effects of inoculation with arbuscular mycorrhizal fungi on growth and water stress tolerance of Medicago sativa in arid region of Tunisia. Int. J. Clin. Biol. Sci. 2: 10-29.

Malhi G.S., Kaur M., Kaushik P., Alyemeni M.N., Alsahli A.A., Ahmad P. 2021. Arbuscular mycorrhiza in combating abiotic stresses in vegetables: An eco-friendly approach. Saudi J. Biol. Sci. 28: 1465-1476.

Manga A., Ndiaye F., Diop T.A. 2018. Le champignon arbusculaire Glomus aggregatum améliore la nutrition minérale de Acacia seyal soumis au stress salin progressif. Int. J. Biol. Chem. Sci. 11: 2352.

Marulanda A., Porcel R., Barea J.M., Azcón R. 2007. Drought tolerance and antioxidant activities in lavender plants colonized by native drought-tolerant or drought-sensitive Glomus species. Microb. Ecol. 54: 543-552.

Mathieu C., Pieltain F., 2003. Analyse Chimique des Sols - Méthodes Choisies. Editions Lavoisier, Tec et Doc, Paris, 389 p.

Mc Gonigles T.P., Millers M.H., Evans D.G., Fairchild G.L., Swan J.A. 1990. A new method which gives an objective measure of colonization of roots by vesicular-arbuscular mycorrhizal fungi. New Phytol. 115: 495-501.

Michaletti A., Naghavi M.R., Toorchi M., Zolla L., Rinalducci S. 2018. Metabolomics and proteomics reveal drought-stress responses of leaf tissues from spring-wheat. Sci. Rep. 8: 5710.

Mohamed H.I., Latif H.H. 2017. Improvement of drought tolerance of soybean plants by using methyl jasmonate. Physiol. Mol. Biol. Plants 23: 545-556

Nelsen C.E., Safir G.R. 1982. Increased drought tolerance of mycorrhizal onion plants caused by improved phosphorus nutrition. Planta 154: 407-413.

Padmavathi T., Dikshit R., Seshagiri S. 2016. Influence of Rhizophagus spp. and burkholderia seminalis on the growth of tomato (Lycopersicon esculatum) and bell pepper (Capsicum annuum) under drought stress. Comm. Soil Sci. Plant Anal. 47: 1975-1984.

Palacios C.E., Nagai A., Torres P., Avelino Rodrigues J., Salatino A. 2021. Concentrations of tannins of cultivars of sorghum cultivated in Brazil, as determined by four quantification methods. Food Chem. 337: 127970.

Parkash V., Singh, S. 2020. A review on potential plant-based water stress indicators for vegetable crops. Sustainability 12: 3945.
Pedone-Bonfim M.V.L., da Silva, F.S.B., Maia L.C. 2015. Production of secondary metabolites by mycorrhizal plants with medicinal or nutritional potential. Acta Physiol. Plant. 37: 27.

Pei Y., Siemann E., Tian B., Ding J. 2020. Root flavonoids are related to enhanced AMF colonization of an invasive tree. AoB Plants 12: 1-7.

Petterson D.S. 2016. The legumes and pseudocereals. Reference Module in Food Science 2: 166-174.

Pyrzynska K., Pękal A. 2013. Application of free radical diphenylpicrylhydrazyl (DPPH) to estimate the antioxidant capacity of food samples. Anal. Meth. 5: 4288-4295.

Redon P.O., Béguiristain T., Leyval C., 2009. Differential effects of AM fungal isolates on Medicago truncatula growth and metal uptake in a multimetallic $(\mathrm{Cd}, \mathrm{Zn}, \mathrm{Pb})$ contaminated agricultural soil. Mycorrhiza 19: 187-195.

Regnault R.C., Philigene B.J.R., Vincent C. 2008. Biopesticides d'Origine Vegetale. Lavoisier, Paris. 597 p.

Rover M.R., Brown R.C. 2013. Quantification of total phenols in bio-oil using the folin-ciocalteu method. J. Anal. Appl. Pyrol. 104: 366-371.

Ruiz-Lozano J.M., Aroca R., Zamarreño Á.M., Molina S., AndreoJimenez B., Porcel R., García-Mina J.M., Ruyter-Spira C., López-Ráez J.A. 2015. Arbuscular mycorrhizal symbiosis induces strigolactone biosynthesis under drought and improves drought tolerance in lettuce and tomato. Plant Cell Environ. 39: 441-452.

Sánchez-Blanco M. J., Álvarez S., Ortuño M.F., Ruiz-Sánchez, M.C., 2014. Root system response to drought and salinity: root distribution and water transport. In: Morte A., Varma A. (eds.) Root Engineering. Springer, Berlin, pp. 325-352.

Sanchez-Morzeno C. 2002. Methods used to evaluate the free radical scavenging activity in foods and biological systems. Food Sci. Technol. Int. 8: 121-139.

Shah A., Smith D.L. 2020. Flavonoids in agriculture: chemistry and roles in biotic and abiotic stress responses, and microbial associations. Agronomy 10: 1209

Shao H.B., Chu L.Y., Shao M.A., Abdul Jaleel C., Hong-Mei M., 2008. Higher plant antioxidants and redox signaling under environmental stresses. C. R. Biol. 331: 433-441.

Singh S., Prasad S., Yadav V., Kumar A., Jaiswal B., Kumar A., Khan N.A., Dwivedi D.K., 2018. Effect of drought stress on yield and yield components of rice (Oryza sativa L.) genotypes. Int. J. Curr. Microbiol. Appl. Sci. 7: 2752-2759.

Sohrabi Y., Heidari G., Weisany W., Golezani K.G., Mohammadi K. 2012. Changes of antioxidative enzymes, lipid peroxidation and chlorophyll concentration in chickpea types colonized by different Glomus species under drought stress. Symbiosis 56: 5-18.

Subramanian,K., Santhanakrishnan P., Balasubramanian P. 2006. Responses of field grown tomato plants to arbuscular mycorrhizal fungal colonization under varying intensities of drought stress. Sci. Hortic. 107: 245-253.

Teotia P., Kumar M., Prasad R., Kumar V., Tuteja N., Varma A. 2017. Mobilization of micronutrients by mycorrhizal fungi. In: Varma et al. (eds.) Mycorrhiza - Function, Diversity, State of the Art. Springer International Publishing.

Thakur J., Shinde B.P., 2020. Effect of water stress and AM fungi on the growth performance of pea plant. Int. J. Appl. Biol. 4: 36-42.

Vierheilig H., Coughlan A.P., Wyss U., Piché Y. 1998. Ink and vinegar, a simple staining technique for arbuscular- 
mycorrhizal fungi. Appl. Environ. Microbiol. 64: 5004-5007.

Walter M. H., Strack D. 2011. Carotenoids and their cleavage products: Biosynthesis and functions. Nat. Prod. Rep. 28: 663.

Wu Q.S., Zou Y.N. 2017. Arbuscular mycorrhizal fungi and tolerance of drought stress in plants. In: Wu (ed.) Arbuscular Mycorrhizas and Stress Tolerance of Plants. Springer, pp. 25-41.

Wu Q.-S., Zou Y.-N., Abd-Allah E.F. 2014. Mycorrhizal association and ROS in plants. In: Ahmad P. (ed.) Oxidative Damage to Plants: Antioxidant Networks and Signaling. Elsevier, pp. 453475.
Yoneyama K., Natsume M. 2010. Allelochemicals for plant-plant and plant-microbe interactions. In: Townsend C.A., Ebizuka Y. (eds.) Comprehensive Natural Products II. Chemistry and Biology. Vol. 4. Elsevier, pp. 539-561.

Zou Y.N., Wang P., Liu C.Y., Ni, Q.D., Zhang D.J., Wu Q.S., 2017. Mycorrhizal trifoliate orange has greater root adaptation of morphology and phytohormones in response to drought stress. Sci. Rep. 7: 41134. 